
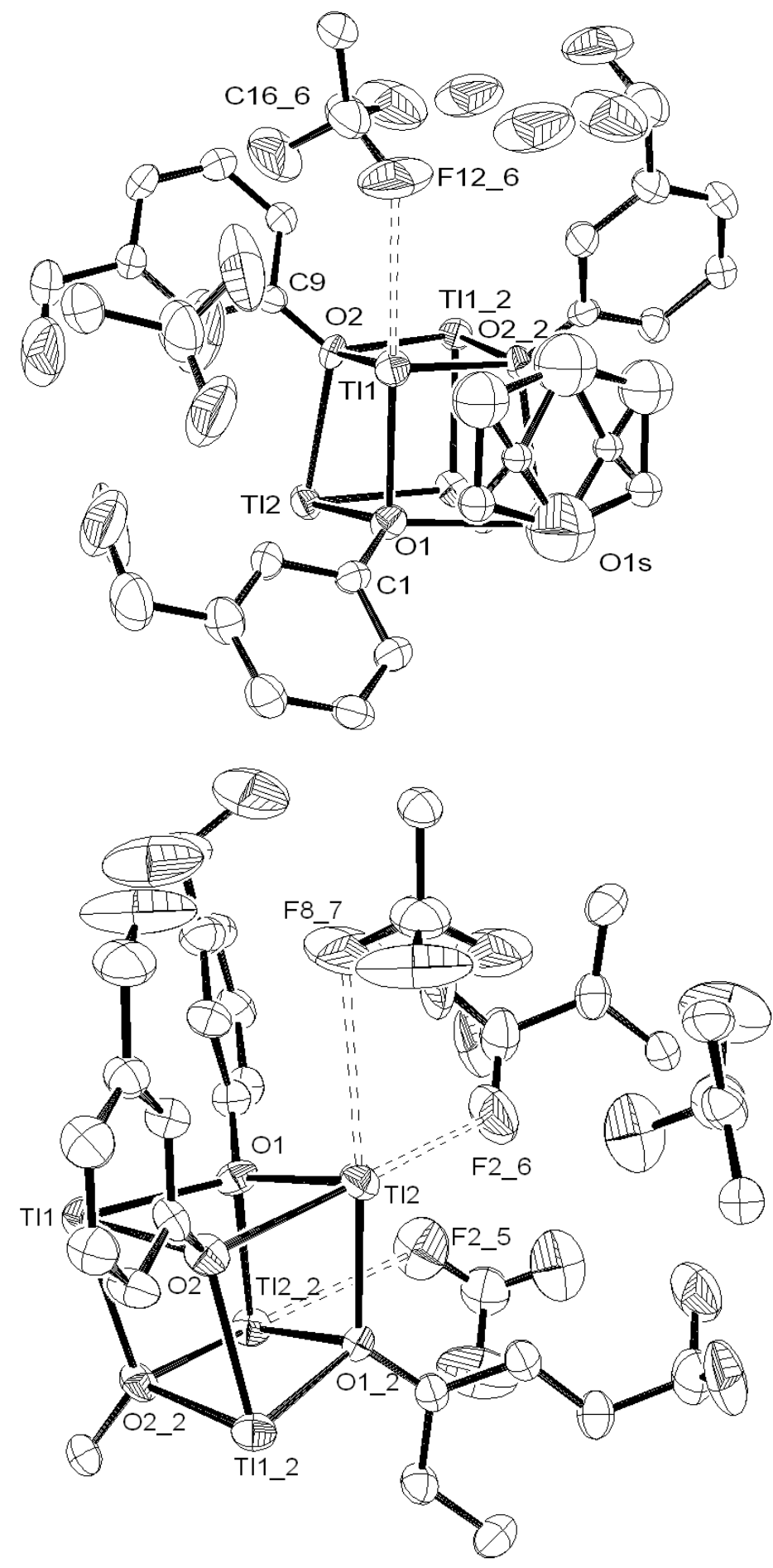

Supplementary Figure S1. ORTEP of 1 with ellipsoids at the 50\% level showing intermolecular contact between (top) $\mathrm{Tl}(1)-\mathrm{F}\left(12 \_6\right) 3.363(6) \AA$ and (bottom) $\mathrm{Tl}(2)$ -

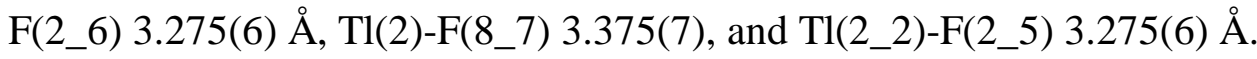




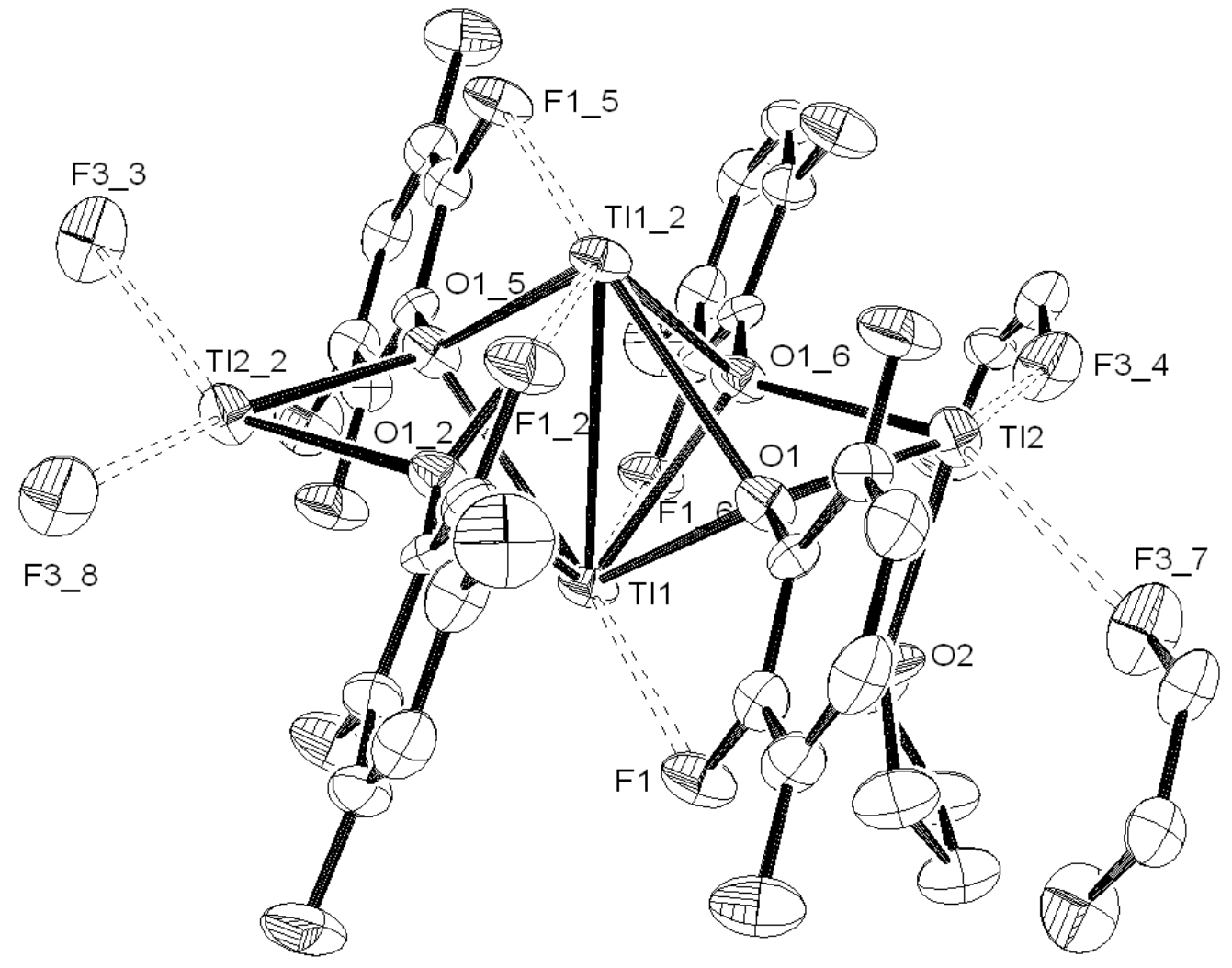

Supplementary Figure S2. ORTEP of 2 with ellipsoids at the 50\% level showing the intramolecular contact between $\mathrm{Tl}(1)-\mathrm{F}(1) 3.252(8) \AA$ and intermolecular contact between $\mathrm{Tl}(2)-\mathrm{F}\left(3 \_4\right) 3.237(8)(\AA)$. 


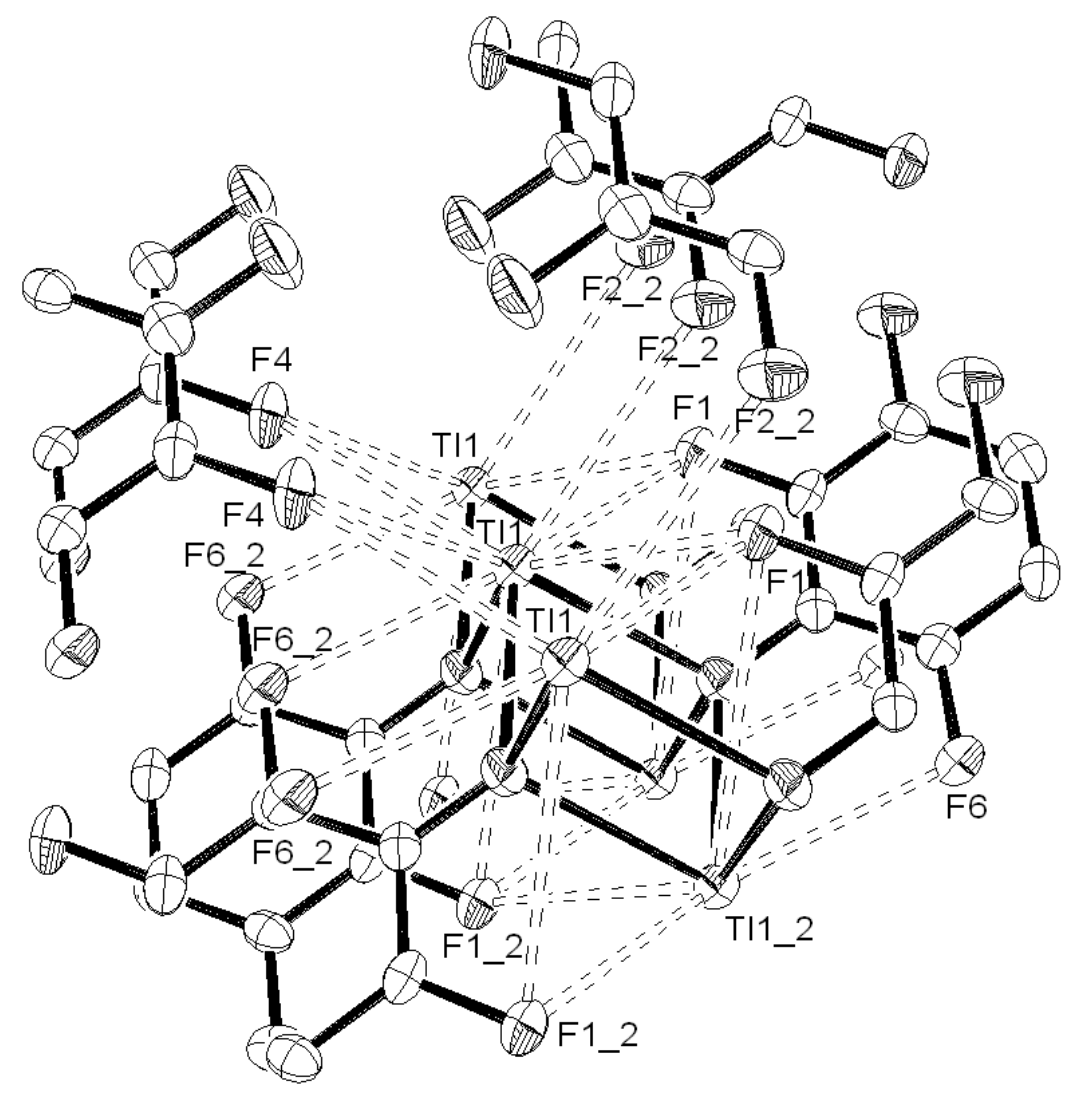

Supplementary Figure S3. ORTEP of $\mathbf{2 b}$ with ellipsoids at the $50 \%$ level showing the intrachain contacts between $\mathrm{Tl}(1)-\mathrm{F}(1)$ and $\mathrm{Tl}(1)-\mathrm{F}(6)$ of $3.053(4)$ and $3.020(4) \AA$ respectively and interchain contacts ( $\mathrm{A})$ of $\mathrm{Tl}(1)-\mathrm{F}(1) 3.277(4), \mathrm{Tl}(1)-\mathrm{F}\left(2 \_2\right) 3.424(5)$, and $\mathrm{Tl}(1)-\mathrm{F}(4) 3.268(4)$. 


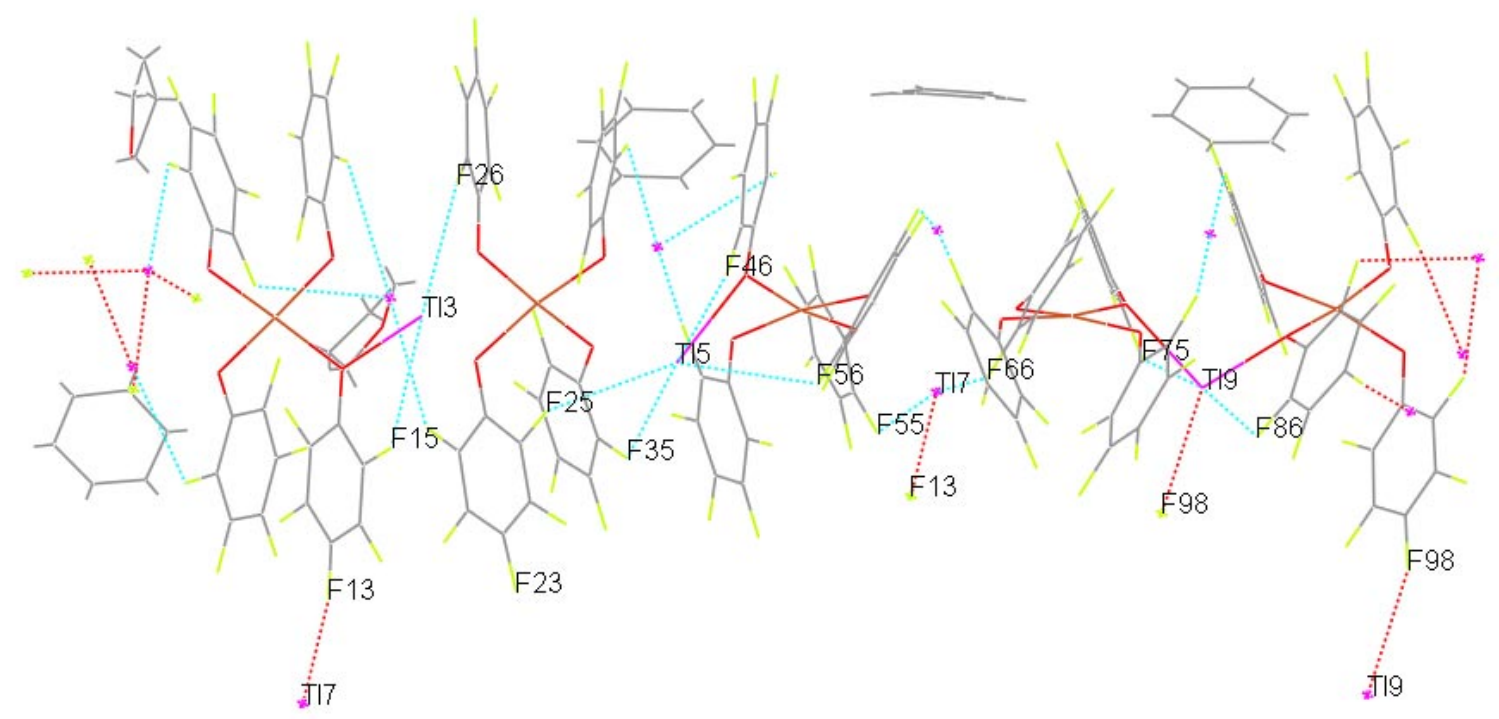

Supplementary Figure S4. Wire-frame drawing showing the intramolecular (turquoise) contacts $(\AA)$ of $\mathrm{Tl}(3)-\mathrm{F}(15) 3.135(8)$ and $\mathrm{Tl}(3)-\mathrm{F}(26) 3.170(10)$; $\mathrm{Tl}(5)-\mathrm{F}(25)$ 3.366(8), $\mathrm{Tl}(5)-\mathrm{F}(35) \quad 3.062(7), \quad \mathrm{Tl}(5)-\mathrm{F}(46) \quad 3.072(9), \quad$ and $\mathrm{Tl}(5)-\mathrm{F}(56) \quad 3.340(7) ; \quad \mathrm{Tl}(7)-\mathrm{F}(55)$ 3.084(10), and $\mathrm{Tl}(7)-\mathrm{F}(66) 3.108(8)$; $\mathrm{Tl}(9)-\mathrm{F}(75)$ 3.078(7) and $\mathrm{Tl}(9)-\mathrm{F}(86)$ 3.142(7). There are also intermolecular (red dotted) Tl-F contacts $(\AA)$ less than $3.5 \AA$ between Tl(5)-F(23) 3.438(9); Tl(7)-F(13) 3.202(9); Tl(9)-F(98) 3.135(10). 

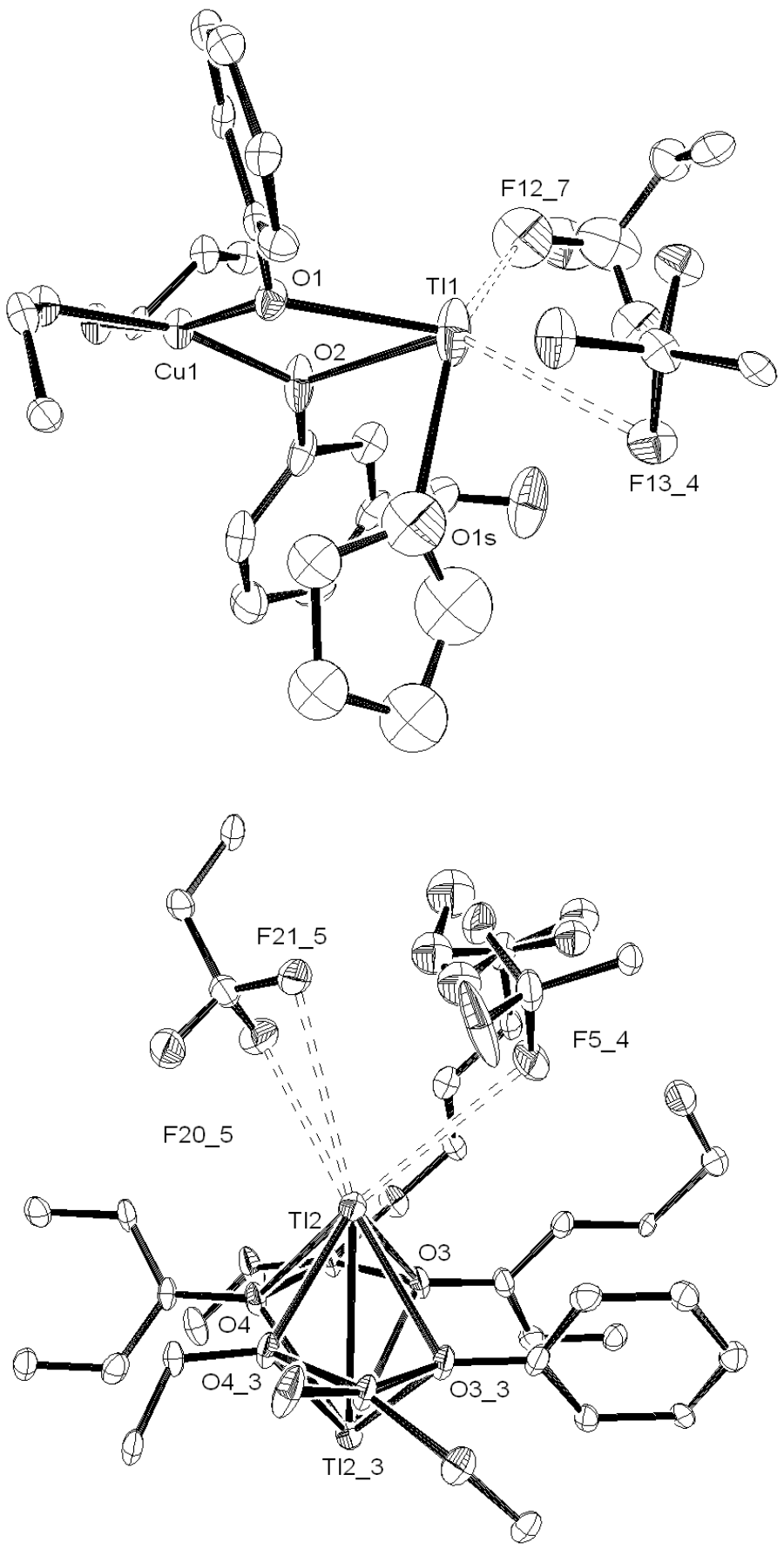

Supplementary Figure S5. ORTEP of $\mathbf{5}$ with ellipsoids at the 50\% level showing the intermolecular contacts of $\mathrm{Tl}(1)-\mathrm{F}\left(12 \_7\right)$ and $\mathrm{Tl}(1)-\mathrm{F}\left(13 \_4\right)$ at 3.456 and $3.483 \AA$ (top) and between $\mathrm{Tl}(2)-\mathrm{F}\left(5 \_4\right), \mathrm{Tl}(2)-\mathrm{F}\left(20 \_5\right)$, and $\mathrm{Tl}(2)-\mathrm{F}\left(21 \_5\right)$ at an average distance of $3.44(8)$ 


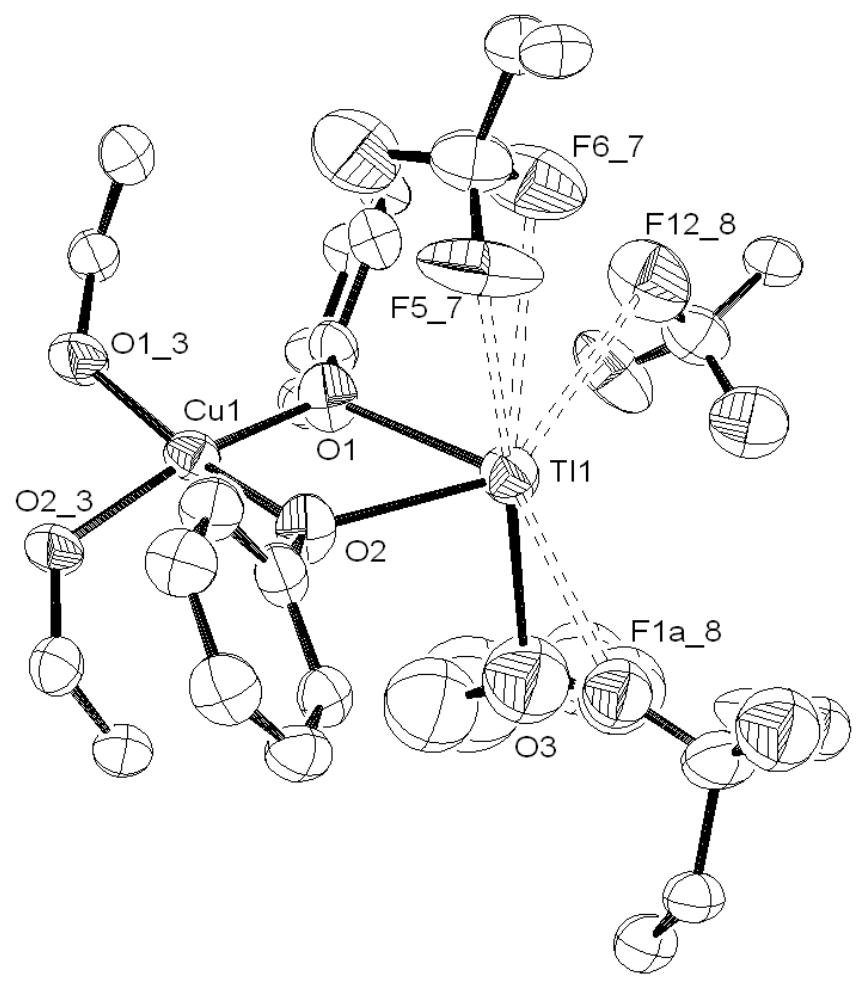

Supplementary Figure S6. ORTEP of $\mathbf{5 b}$ with ellipsoids at the $50 \%$ level showing the intermolecular contacts of $\mathrm{Tl}(1)-\mathrm{F}\left(1 \mathrm{a} \_8\right) 3.07(2), \mathrm{Tl}(1)-\mathrm{F}\left(5 \_7\right) 3.360$ (7), $\mathrm{Tl}(1)-\mathrm{F}\left(6 \_7\right)$ 3.332(6), and Tl(1)-F(12_8) at a distance of 3.461(6) A. 

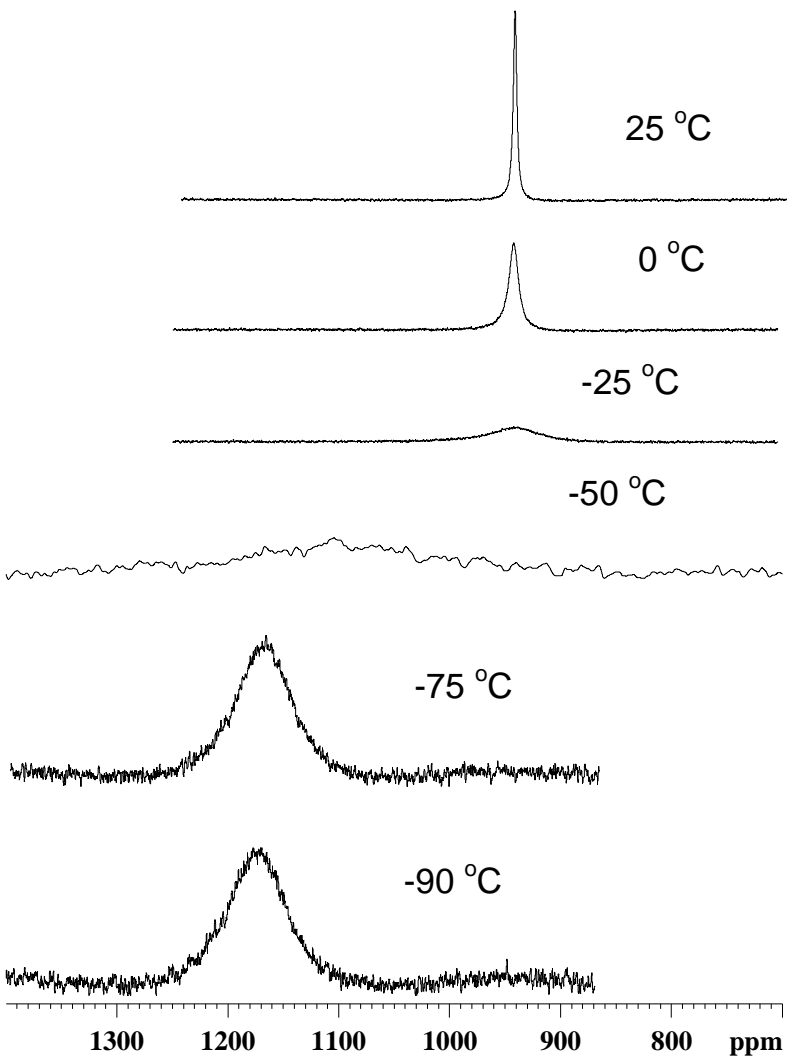

Supplementary Figure S7. Variable temperature ${ }^{205} \mathrm{Tl}$ spectra of $\mathbf{2}$ in $\mathrm{d}_{6}$-acetone. 


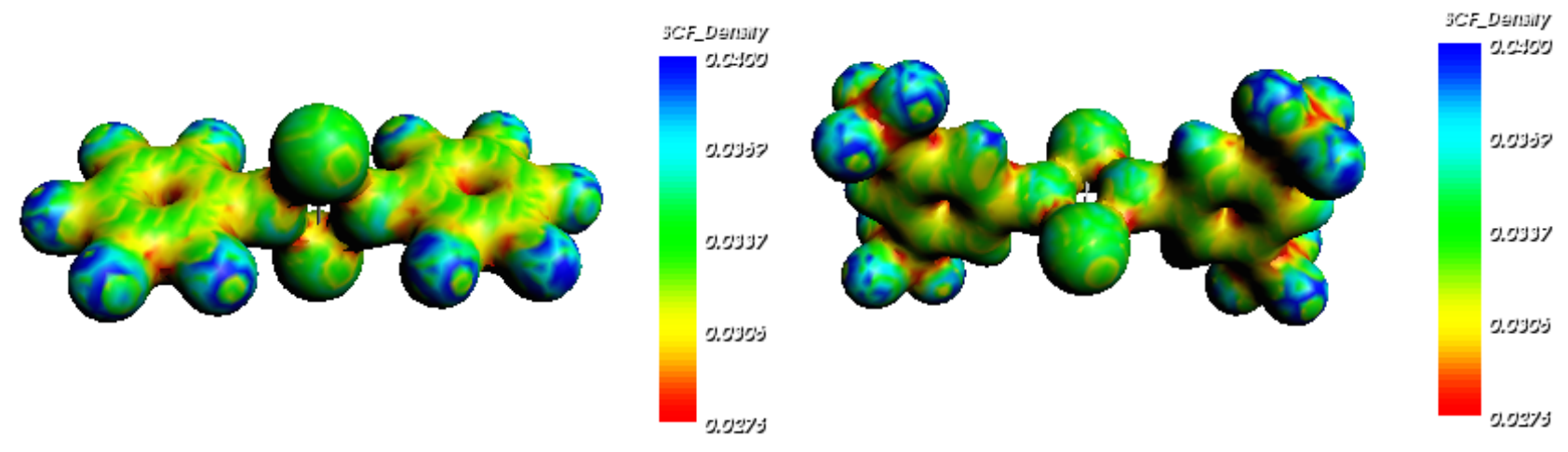

Supplementary Figure S8. SCF density diagrams for the hypothetical dimers $\left(\mathrm{TlOAr}^{\mathrm{F}}\right)_{2}$, II, and (TlOAr' $)_{2}$, I. The scale covers a range of 0.0275 to 0.0400 electrons. 


\section{Fluorescence Spectra of $\{\mathrm{TIOAr}\}_{4}$ Compounds}

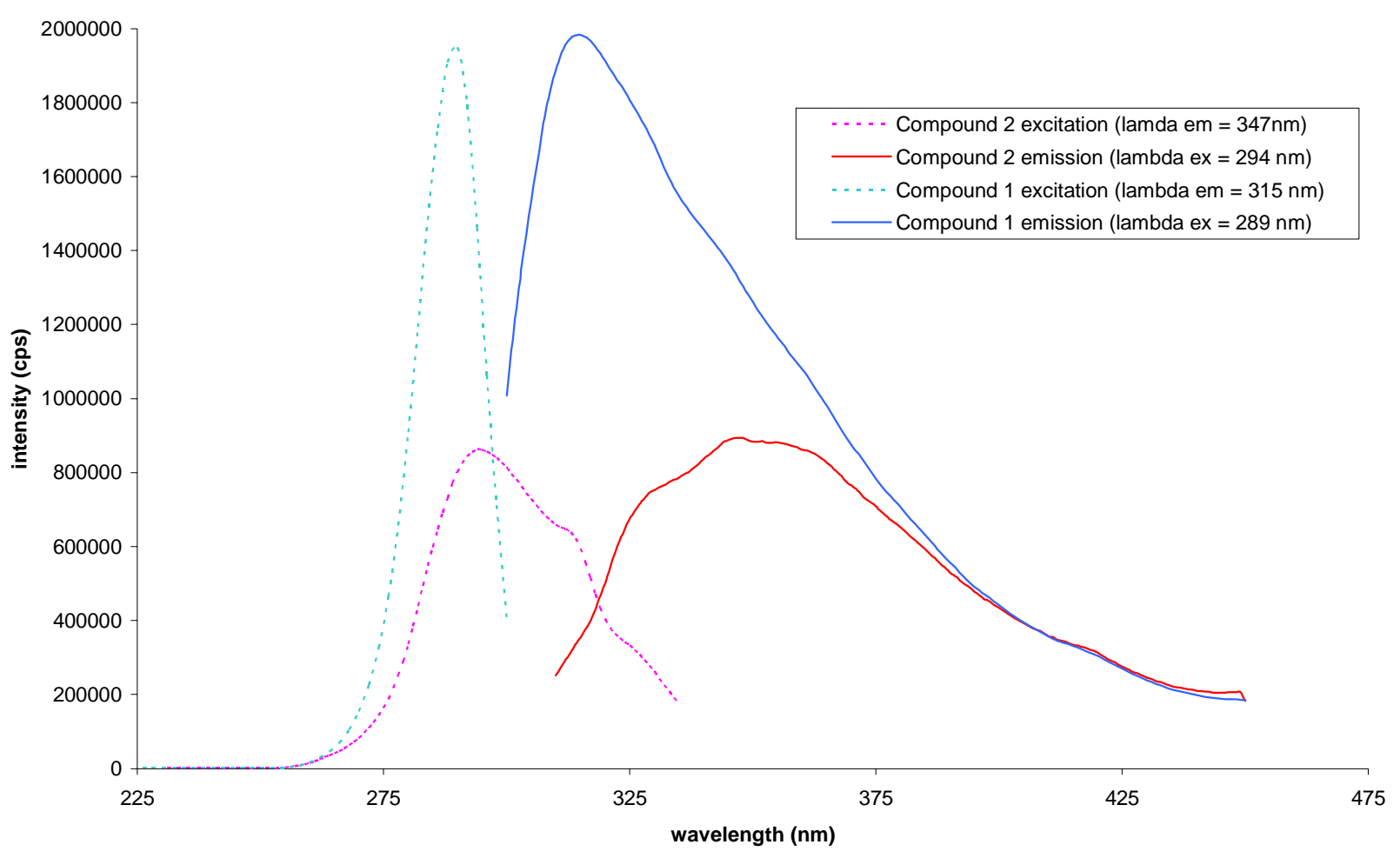

Supplementary Figure S9. Fluorescence spectra of compounds 1 and $\mathbf{2}$ in THF at room temperature. 